\title{
BROOKHGWEN
}

NATIONAL LABORATORY

BNL-77927-2007-IR

\section{Performance of the Capstone C30 Microturbine on Biodiesel Blends}

\author{
C. R. Krishna
}

January 2007

\section{Energy Sciences and Technology/Energy Resources Division \\ Brookhaven National Laboratory \\ P.O. Box 5000 \\ Upton, NY 11973-5000 \\ www.bnl.gov}

\begin{abstract}
Notice: This manuscript has been authored by employees of Brookhaven Science Associates, LLC under Contract No. DE-AC02-98CH10886 with the U.S. Department of Energy. The publisher by accepting the manuscript for publication acknowledges that the United States Government retains a non-exclusive, paid-up, irrevocable, world-wide license to publish or reproduce the published form of this manuscript, or allow others to do so, for United States Government purposes.
\end{abstract}




\section{DISCLAIMER}

This report was prepared as an account of work sponsored by an agency of the United States Government. Neither the United States Government nor any agency thereof, nor any of their employees, nor any of their contractors, subcontractors, or their employees, makes any warranty, express or implied, or assumes any legal liability or responsibility for the accuracy, completeness, or any third party's use or the results of such use of any information, apparatus, product, or process disclosed, or represents that its use would not infringe privately owned rights. Reference herein to any specific commercial product, process, or service by trade name, trademark, manufacturer, or otherwise, does not necessarily constitute or imply its endorsement, recommendation, or favoring by the United States Government or any agency thereof or its contractors or subcontractors. The views and opinions of authors expressed herein do not necessarily state or reflect those of the United States Government or any agency thereof. 


\section{Introduction}

This report will describe the tests of biodiesel blends as a fuel in a Capstone oil fired microturbine (C30) with a nominal rating of $30 \mathrm{~kW}$. The blends, in ASTM \#2 heating oil, ranged from $0 \%$ to $100 \%$ biodiesel. No changes were made to the microturbine system for operation on the blends. Apart from the data that the control computer acquires on various turbine parameters, measurements were made in the hot gas exhaust from the turbine. The results from this performance testing and from the atomization tests reported previously [1] provide some insight into the use of biodiesel blends in microturbines of this type. The routine use of such blends would need more tests to establish that the life of the critical components of the microturbine are not diminished from what they are on the baseline diesel or heating fuel. Of course, the extension to 'widespread' use of such blends in generating systems based on the microturbine is also determined by economic and other considerations.

\section{Experimental work}

The Capstone microturbine is located just outside to the north of building 526 at Brookhaven National Laboratory. Figure 1 below is a picture of the turbine from the front. The turbine on the left of the picture is he oil fired system where these tests were conducted. The one on the right (in the back) is a gas fired $30 \mathrm{~kW}$ Capstone turbine. Figure 2 is a picture from the side with the outside cover open and shows the 'guts' of the system in a little more detail.

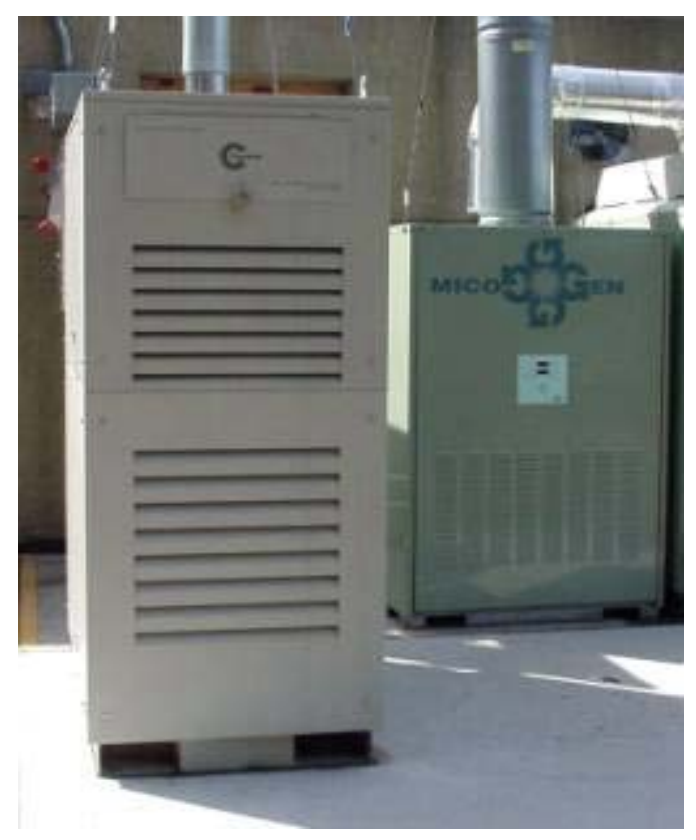

Figure 1. Oil Fired Capstone C30 Microturbine 


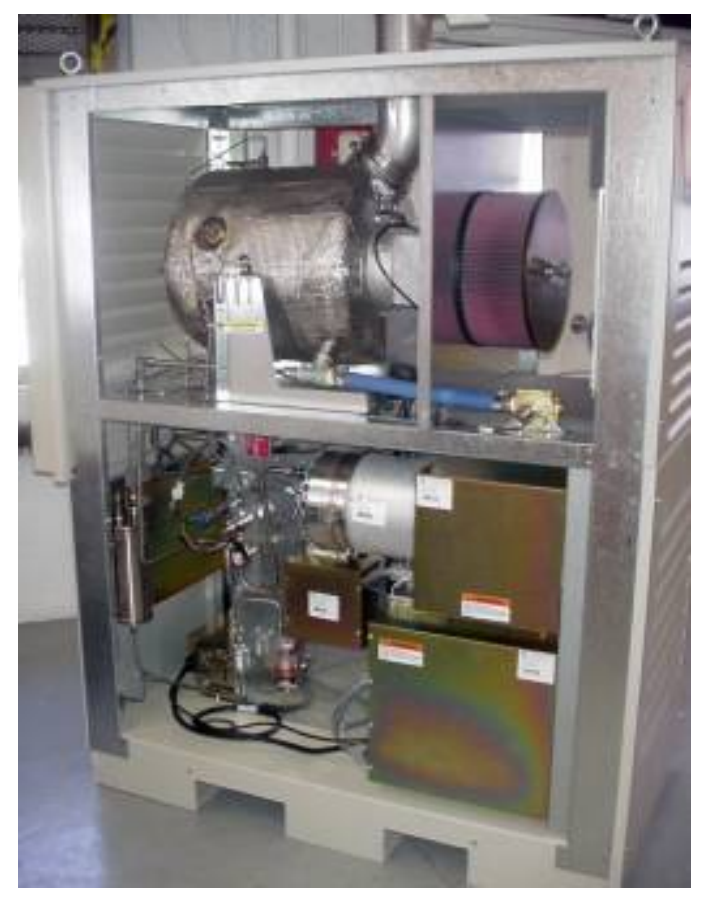

Figure 2. Side View of the Capstone Microturbine

The fuel blends were made with biodiesel (according to the supplier, it was made from soy oil) to ASTM 6751 specifications. The heating oil is to ASTM \#2 specifications and is from a tank that is used in research on home heating boilers and furnaces. The blends are made in volumetric ratios, that is, B20 is $20 \%$ by volume biodiesel and $80 \%$ by volume of heating oil, in small plastic carboys. The microturbine is usually started on neat heating oil, warmed up and then switched to operate on the blend under test. After the test on the blend, the fuel is switched back to the heating oil and the turbine run for enough time to ensure that the blend is not left over in any part of the fuel system. This was done because it was not known whether any of the parts in the fuel system with which the fuel came in contact, especially non-metallic parts such as seals, seats, and gaskets, were incompatible with biodiesel. It is known that some of the elastomeric material used for manufacturing such parts that are compatible with petroleum based fuels may not maintain their integrity for long periods of time in contact with biodiesel.

The fuel was supplied from inside the building through a volumetric flow meter. The fuel is required to be supplied at a minimum pressure of 3 psig at the inlet to the turbine fuel system and this is accomplished for the blends by means of an auxiliary pump. The turbine is started, controlled and monitored by a computer using Capstone's software. The exhaust measurements are made in the vertical stack, which can be just seen in figure 1 emerging from the top. A sampling system draws, through a sampling line inserted in the vertical stack, exhaust gas, which is fed to a chemi-luminescent NOx analyzer and an Infrared $\mathrm{CO}$ analyzer. The NOx analyzer is a Beckman model 955 and the $\mathrm{CO}$ analyzer is a Fuji Electric Type ZFU 21MY3. A Testo 350 portable analyzer is inserted into the stack for measurements of $\mathrm{O} 2, \mathrm{CO}, \mathrm{NOx}$, and $\mathrm{SO} 2$. Outdoor ambient and 
stack temperatures are measured by thermocouples. The NOx and $\mathrm{CO}$ meters are calibrated using calibration gases of known composition with $\mathrm{NOx}$ and $\mathrm{CO}$ in the measurement range. The TESTO 350 is calibrated at the factory. Figure 3 shows the NOx and CO instruments and also the fuel flow meter (ISTEC Corporation Type VZO 4USG) on the wall.

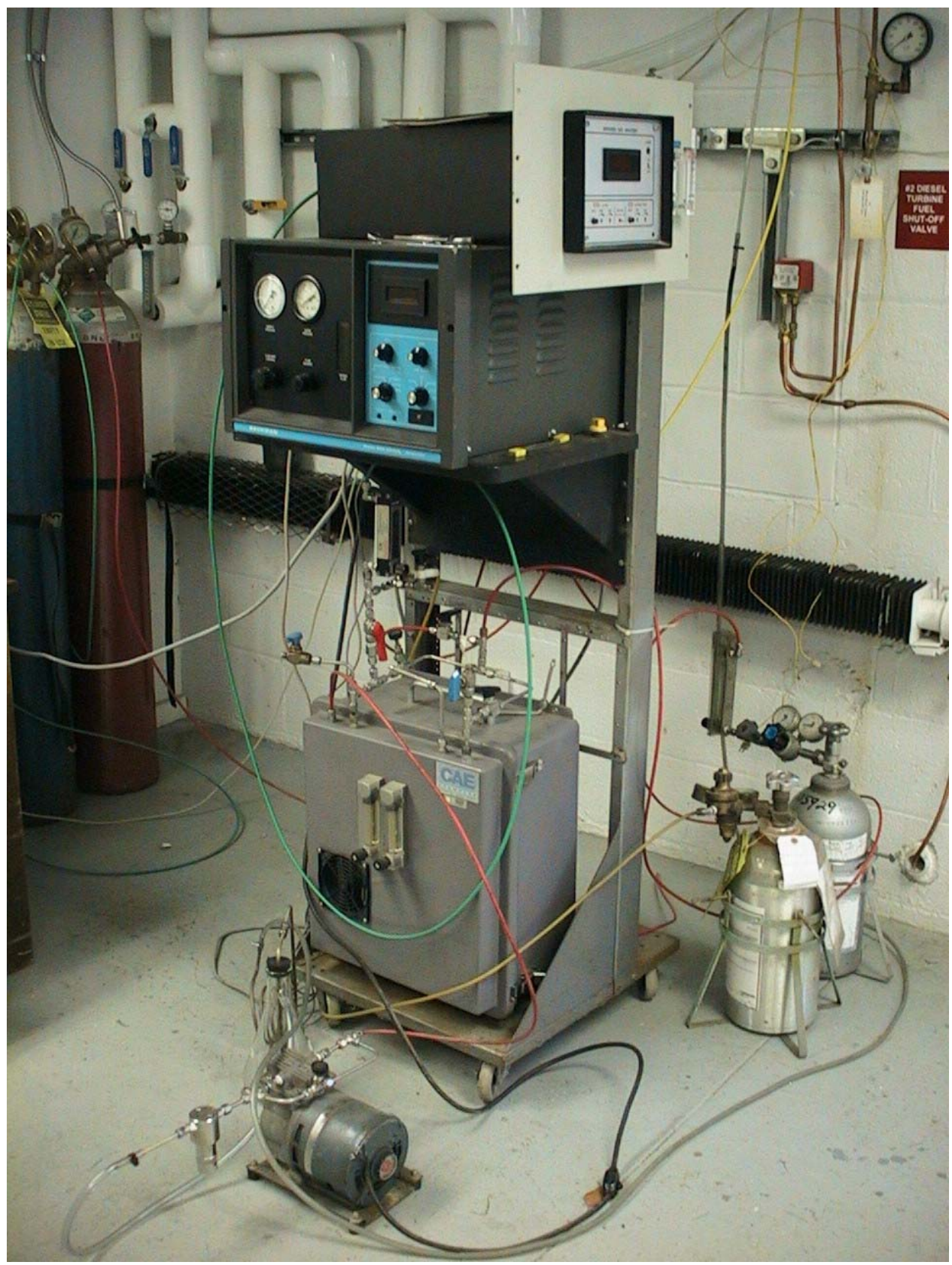

Figure 3. Instrumentation

The tests were run at a number of power settings from the maximum down to $10 \mathrm{~kW}$ for each blend. The tests were spread over several days of actual testing and the test days occurred over a period of months. As the turbine is located outside the building and draws ambient air, the air temperature varied over the 
period of the tests. As is well known, a turbine's output is sensitive to ambient temperature and hence in some of the tests the maximum power output of $\sim 30 \mathrm{~kW}$ was not attained. The output was not limited by the blends up to B 100 in any way that could be discerned, that is to say, the engine fuel system and the operating parameters are capable of accommodating the changes in fuel parameters (heating value, viscosity etc.) from blending with biodiesel.

\section{Results and Discussion}

The results will be presented as emission measurements as a function of engine thermal input calculated from the fuel flow rate and the nominal higher heating value (HHV) for the specific blend being used or as a function of the power output as recorded by the Capstone monitoring system. It is believed that this will help in comparing the performance on the blends with that on the baseline heating fuel on a consistent basis. Figure 4 shows the sulfur dioxide (SO2) emitted at a number of power settings. The measured values are corrected to $15 \%$ Oxygen as is typical in reporting turbine emission data, from the measured concentrations in the stack. As is known, the effect of adding biodiesel to the blend is to lower the sulfur content of the fuel and therefore the consequent emission of sulfur dioxide. This is an obvious environmental benefit of blending biodiesel with high sulfur heating oil.

SO2 at $15 \%$ O2

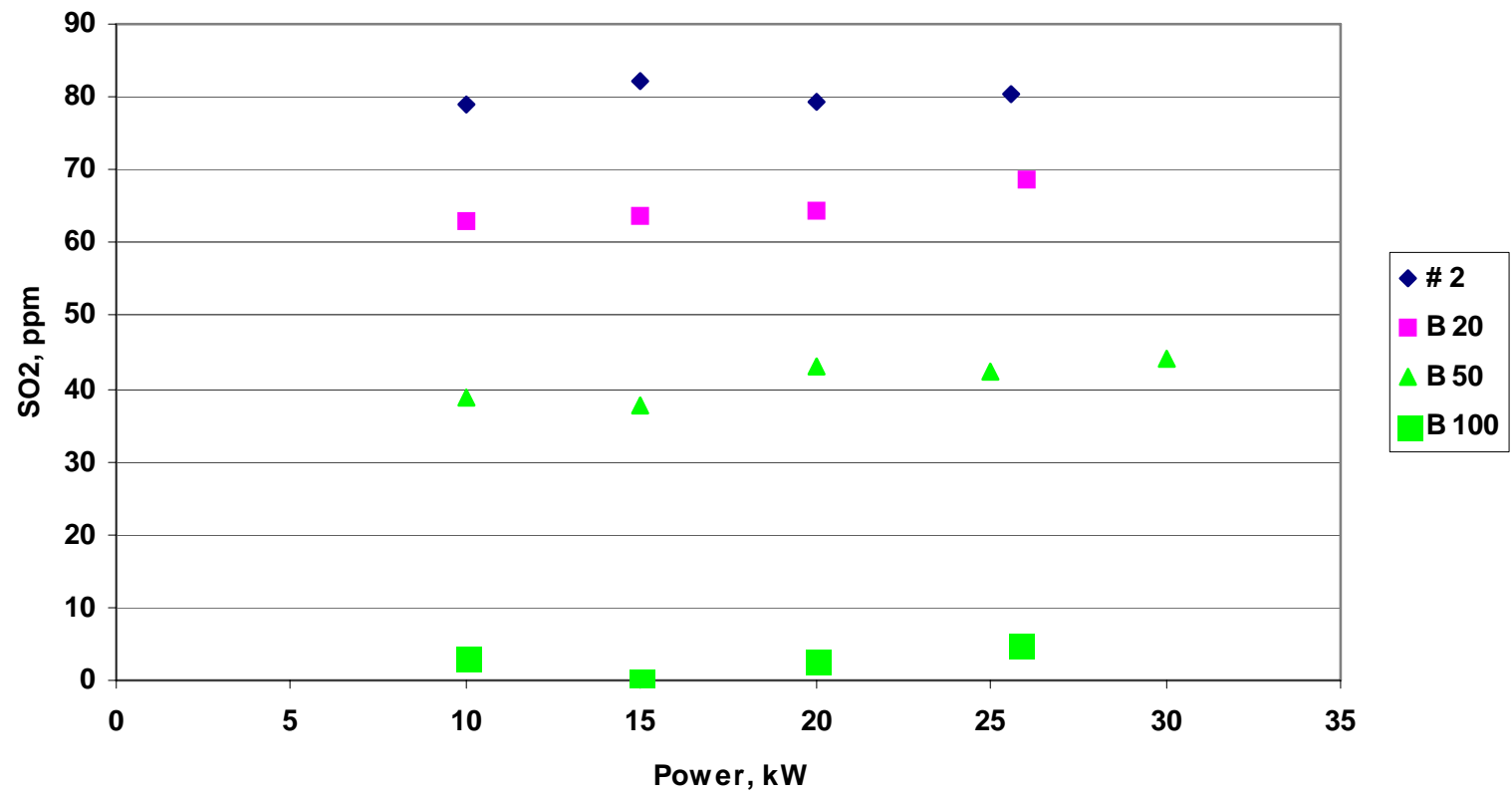

Figure 4. Sulfur Dioxide Emission from Blends (corrected to 15\% O2)

However, in boiler applications, the practice is to present the emission values corrected to $3 \%$ oxygen. While these changes are merely algebraic, the data will be presented both ways to facilitate comparison. So, figure 5 presents the same data that is in figure 4 in this way. 
SO2 at $3 \% 02$

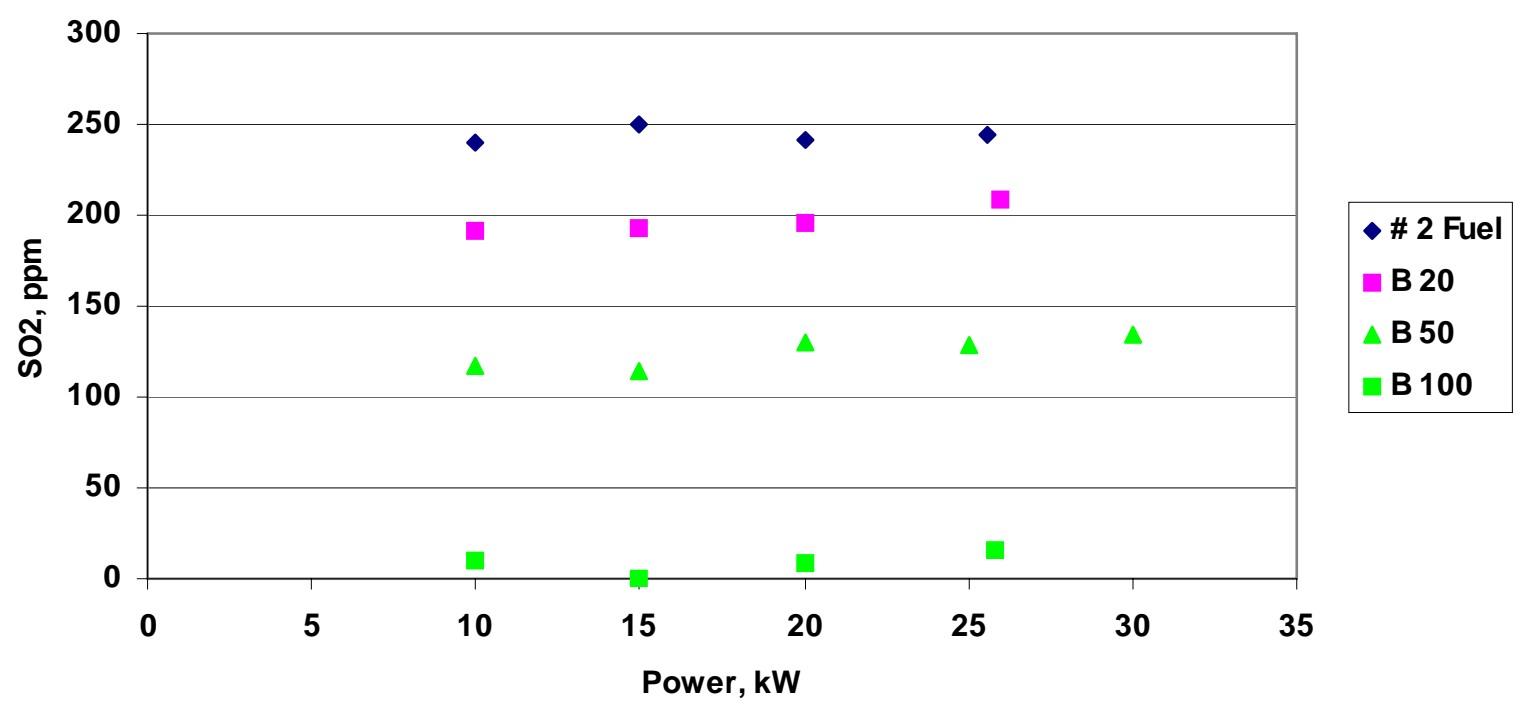

Figure 5. Sulfur Dioxide Emission from Blends (corrected to 3\% O2)

It should be noted that the $\mathrm{SO} 2$ emission concentration is fairly constant across the power levels as is to be expected.

Typically, as fuel input and power output are reduced, the combustion temperature decreases, making it more difficult to oxidize the carbon monoxide produced in hydrocarbon combustion. Hence, it is of interest to see how the substitution of the biodiesel for the heating oil affects this. This is shown in figures 6 and 7 below, again corrected to 3\% and 15\% oxygen respectively. In this case, the 'corrected' CO levels in the stack are plotted against the fuel thermal input rate to the turbine, as it is a more direct indication of the combustion chamber temperature. As expected, the $\mathrm{CO}$ emission is higher at the lower input rates for the baseline fuel and the blends. However, it does seem that the performance with the biodiesel blends is significantly better, meaning lower $\mathrm{CO}$ emitted, certainly at these lower input rates, and slightly so at the higher thermal input rates. It is not clear as to what the exact reasons are for this.

The emission of Nitrogen Oxides (NOx) from combustion systems is of significant concern for a variety of reasons. In the use of biodiesel blends in diesel engines, this has been cause for some concern as it has been often observed that NOx tends to go up [1]. However, in small boilers generally, it has been observed that the addition of biodiesel to heating oil tends to lower the NOx emission [2]. The measurements of NOx emissions in our tests are reported in figures 8 and 9 below. As is well known, the production of NOx is a strong function of combustion chamber temperature and hence they are presented in these two figures as a function of the fuel thermal input rate. An interesting observation arises from these figures. At the high fuel thermal input rates or high power outputs, the NOx emitted seems to be about the same for the baseline fuel and the blends. However, as the power output is reduced, the NOx level is significantly lower with the increase of biodiesel in the blend and is lowest with 100\% 
biodiesel. This is an interesting feature, while its significance in terms of turbine operation in practice is not clear. Overall, it does seem that the NOx emission does not increase with the use of this type of biodiesel blend in this microturbine at least.

\section{CO at $3 \% O 2$}

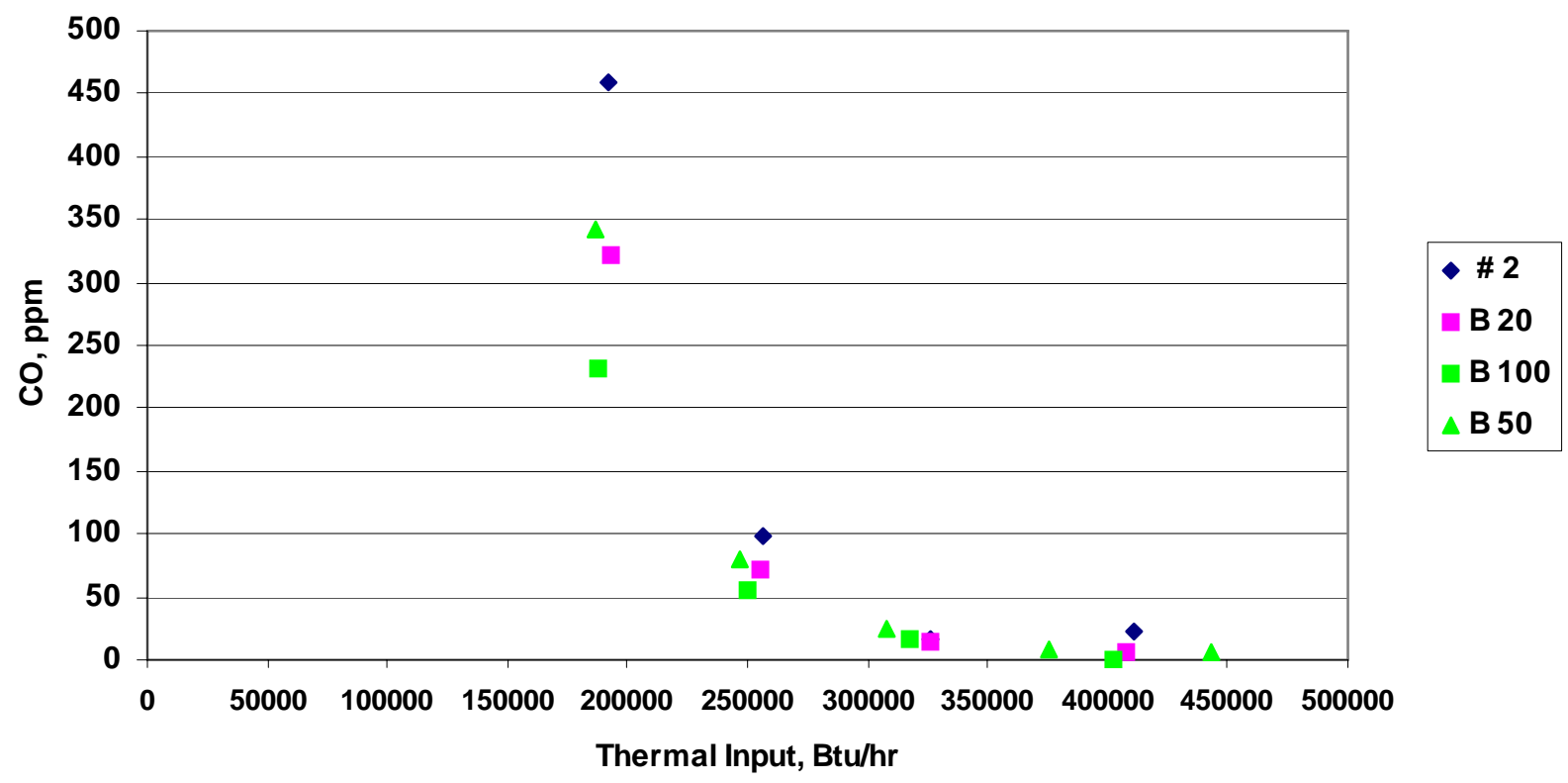

Figure 6. Carbon Monoxide Emission (3\% O2)

\section{CO at $15 \% 02$}

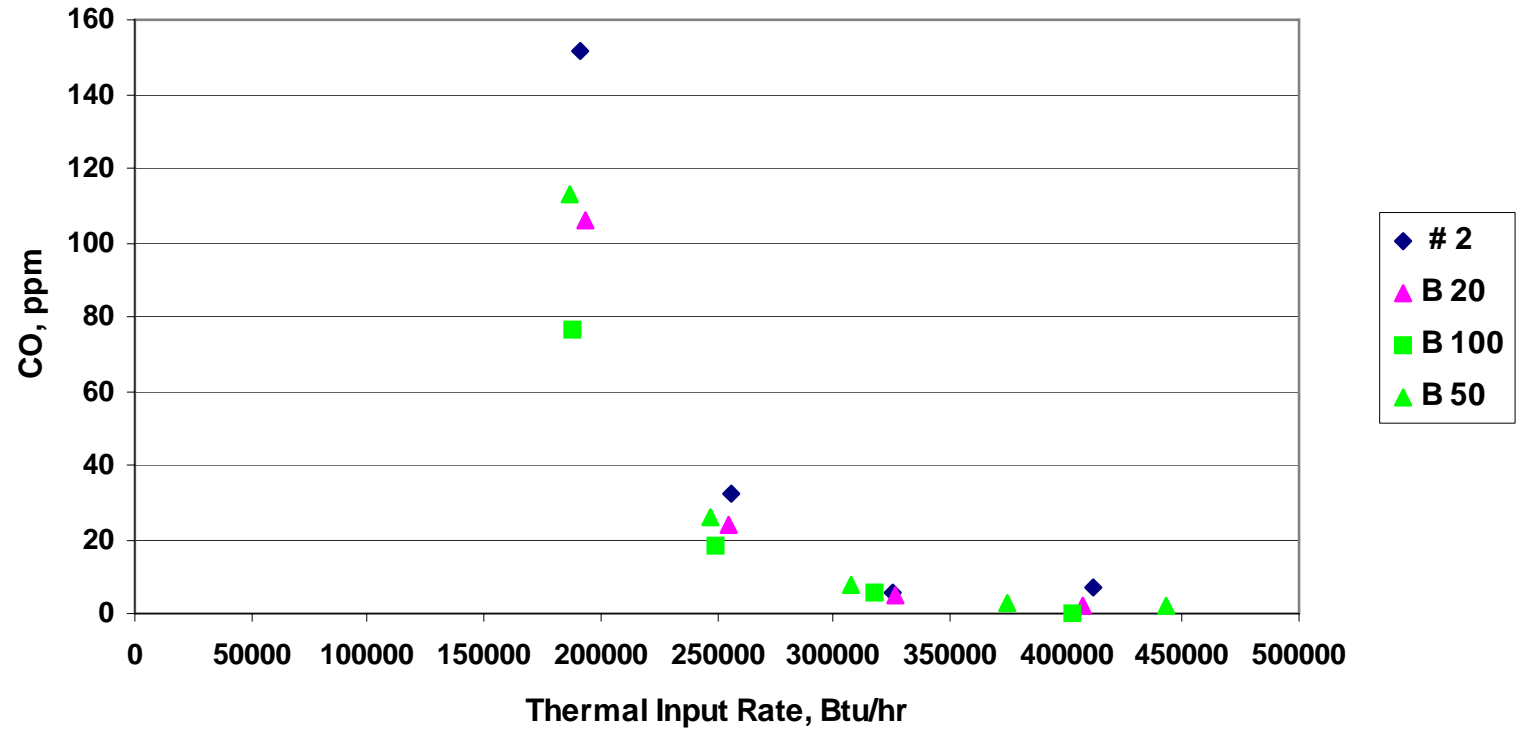

Figure 7. Carbon Monoxide Emission (15\% O2) 
NOx at $3 \% \mathrm{O} 2$

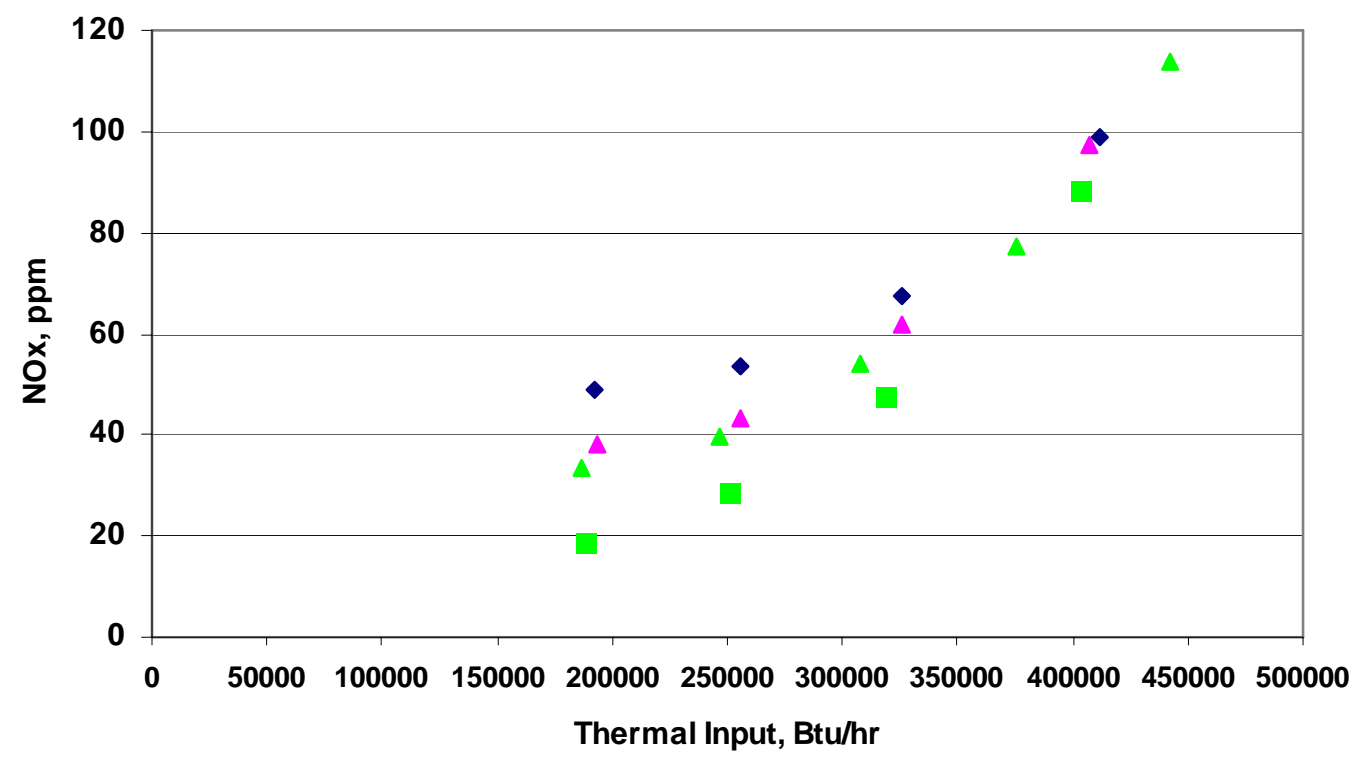

Figure 8. NOx Emission (corrected to $3 \% \mathrm{O} 2$ )

NOx at $15 \% 02$

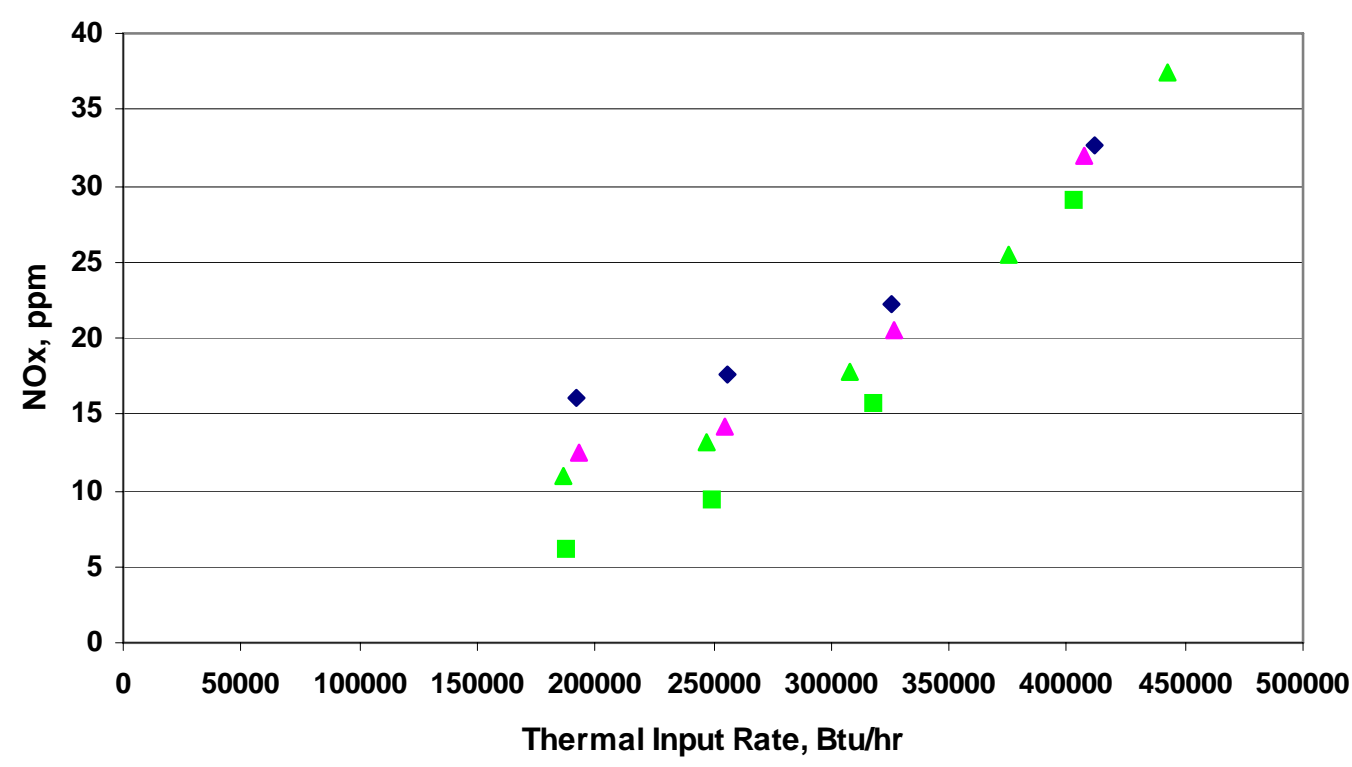

Figure 9. NOx Emission (corrected to $15 \%$ O2)

Figure 10 below compares the calculated efficiencies using the fuel thermal input calculated from the nominal HHV for the blend and the flow rate and the power output reported by Capstone's monitoring software for all the blends tested. As indicated before, the tests were done on different days and hence 
different ambient temperature conditions. There are not any significant changes in efficiency.

\section{Efficiency vs Power}

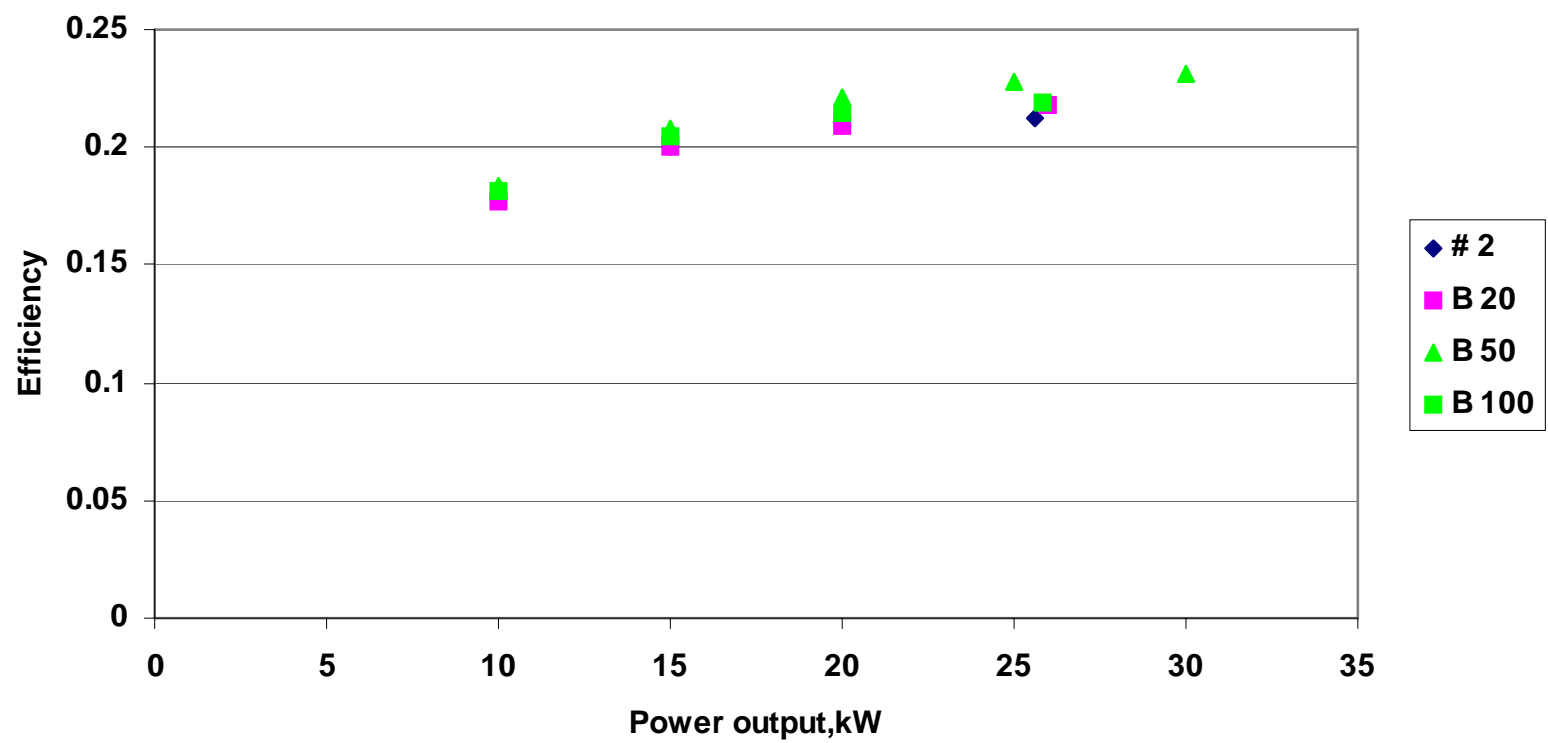

Figure 10. Efficiency of Power Output

As part of the tests, it was considered important to see whether the turbine could be started directly with the blends. As noted before, for the performance tests the starting was done on the \#2 heating oil. Hence, a 'cold' start was demonstrated successfully with B20 and a 'hot' start, that is a start soon after shut down, was demonstrated with B100. Caution was required as the part of the fuel system exposed to the ambient temperature outside the building could cause difficulties with B100 especially if cooled below the cloud point.

\section{Conclusions}

The following conclusions can be made from the testing done here. It should be mentioned that the limited amount of testing done here restricts the applicability of these conclusions to the specific type of biodiesel (made from soy oil to ASTM D6751 specifications) used to make the blends with heating oil to ASTM \#2 specifications.

1. The microturbine can be operated successfully on blends of biodiesel up to $100 \%$ or neat biodiesel. The differences in physical properties do not affect operation. "Cold' or 'warm' starts on all blends are possible. The efficiency of power generation is pretty much unchanged.

2. The benefits of near zero sulfur in the biodiesel manifests in lower sulfur oxide emissions corresponding to the amount of biodiesel in the blend.

3. The addition of biodiesel leads to lower carbon monoxide emissions.

4. The addition of biodiesel does not increase the NOx under high power conditions and lowers it significantly under low power conditions. 
5. Effects of long term operation on fuel system materials, and on the hot components of the turbine have not been studied.

\section{Acknowledgements}

Yusuf celebi deserves thanks for getting the system ready for the tests and helping with the measurements. Tom Butcher is owed thanks for support throughout and for reviewing the report. The Department of Energy is acknowledged for funding the project, with thanks to Don Geiling as the project manager. Thanks to Don Geiling and Debbie Haught at the Department of Energy, who have both been encouraging and supportive. Steve Gillette and Craig Smugeresky of Capstone Turbine Corporation have been very helpful with material and technical support.

\section{References}

1. Robert L. McCormick and Teresa L. Alleman, "Effect of Biodiesel Fuel on Pollutant Emissions from Diesel engine," Chapter 7 in The Biodiesel Handbook (Editors: Gerhard Knothe, Jon Van Gerpen, Jurgen Krahl), 2005.

2. C.R. Krishna, "Biodiesel Blends in Space Heating Equipment," BNL68852, 2001. 